\title{
Research on the Social Responsibility of Corporations in China
}

\author{
Dianwei Qi ${ }^{1}$, Chunhua Feng ${ }^{1} \&$ Meina $\operatorname{Jin}^{1}$ \\ ${ }^{1}$ Chang Chun University of Science and Technology, Changchun, China \\ Correspondence: Dianwei Qi, Chang Chun University of Science and Technology, Changchun 130022, China. \\ E-mail: qidianwei1111@126.com
}

Received: August 30, 2012 Accepted: September 20, 2012 Online Published: November 30, 2012

doi:10.5539/ass.v8n15p184

URL: http://dx.doi.org/10.5539/ass.v8n15p184

\begin{abstract}
It is the consensus of the Chinese enterprises to focus on the sustainable development of enterprises and society and emphasize responsibility and contribution. Compared with the large and medium-sized enterprises, the small and medium enterprises (SME) have fulfilled certain social responsibility and played an irreplaceable role in promoting economic growth, increasing employment, technological innovation and social harmony and stability. However, there are some problems for corporation of China to fulfill their social responsibilities that the paper will discuss, then put forward the measures how to strengthen social responsibility fulfillment.
\end{abstract}

Keywords: central enterprises, the small and medium enterprises (SME), corporate social responsibility (CSR)

\section{Introducation}

In recent years, the corporate social responsibility (CSR) is increasingly concerned by the international and domestic society. More and more enterprises, NGO and other social organizations have put into the social responsibility activities, and the government agencies have also begun to actively participate in institutional arrangement, policy formulation and practice guide of the social responsibility. Internationally, the United Nations officially launched the "Global Compact" program in 2000. International Organization for Standardization started the plan to formulate ISO 26000 international standards of social responsibility in 2004, about 120 countries and international organizations, more than 400 experts to participate in the standard setting. Some multinational companies have to lay down social responsibility codes of conduct, release social responsibility report or sustainability report, which there has been a new trend of global CSR.

Judged from the current situation, China's large and medium-sized corporations have fulfilled CSR well, at the same time the small and medium enterprises (SME) also have fulfilled certain social responsibilities: to promote economic growth, increase employment, carry out technological innovation and social harmony and stability in which SME have played important role. However, there are some problems for SME about their social responsibilities which the paper will discuss on and put forward the measures how to strengthen social responsibility to fulfill.

\section{The Concept of the Corporate Social Responsibility}

The concept of the CSR has been discussed by the domestic and outside forum many times, but it has still reached no agreement. It is generally accepted in the international: enterprises not only generate profits, responsible for the interests of the shareholders, but also bear the social responsibility for staff, society and environment including compliance with business ethics, product safety, occupational health, protection of legitimate labor rights and conservation of resources.

The World Bank defined the CSR as: the collections of the relationship among businesses and key stakeholders, values, disciplines, respect for people, communities and policies and practices of the environment-related. It is commitment which improves the quality of life of the stakeholders and contributes to sustainable development.

In November, 2010, the global social responsibility standard system (ISO26000) was officially released that for the first time summarized the social responsibility concept and practice of the worldwide system. In addition to clarifying the subject and concept of the social responsibility, it also made clear the object of an organization to fulfill their social responsibility: the 7 principles and core themes to fulfill their social responsibilities and provides operation guideline of merging social responsibility into the entire organization which provided clear guidance for the organization to fulfill their social responsibilities. 
All in all, corporations bear the responsibility for compliance laws and offer excellent quality products and services; customers, consumers, employees, supply chain partners, local communities, private welfare organizations and the government are the same as shareholders which are our stakeholders, corporate actions will have an impact on the surrounding environment and social development concerned the interests of all stakeholders. Therefore, in the business operations at the same time, the enterprises should contribute to the environment, community, users, employees and partners and so on.

\section{The Significance of the Enterprises to Fulfill Social Responsibility}

At present, the requirements of fulfillment the CSR increasingly are higher, and at the same time the constraint is stricter; to further implement the scientific development concept and build harmonious society, higher expectations and demands of the CSR are put forward.

\subsection{The Requirements of the Sustain Development and the Constraints of the Resources and the Environment}

China's socio-economic field germination is a profound change in the enterprise survival and development environment facing changes and challenges which has told us we should have a comprehensive plan and the completion of the CSR, to talk about the future of enterprise's core competitiveness.

The constraints of the resources and the environment, the enhancement of social voices, the adjustment of the international division of labor will profoundly affect the future pattern of development and provide an opportunity and momentum for a transmutation. To face the changes of the internal and external environment, the corporations need to blaze new trails and transformation.

\subsection{The Requirements of the Corporation Competition Lift}

In today's world and contemporary China in the economic field, the CSR with the company's product quality, service, reputation, patents and brand has become an element of competition in the market; In particular, in the process of social innovation and transformation, during the dynamic eruption inevitably there will be a lot of chaos, which need to promote social responsibility. The enhancement of innovation and transformation cannot be separated from the CSR, courage and wisdom to fulfill social responsibility cannot be separated from innovation. During the innovation and transformation, the practice of the CSR will be closely with the times, so the concept of the CSR will continue to sublime and strengthen.

What the CSR is stressed helps to strengthen corporate competition. The recent study findings showed a correlation between CSR and the return on equity. When the CSR is emphasis on, corporate financial performance is good. The corporate environmental policy has something to do with economic performance. The studies on 243 enterprises have shown that the close correlation between environmental policy and economic performance that is enhanced with the development of enterprises.

\subsection{The Requirements of the Public}

In recent years, the toxic milk powder incident and other similar incidents occurred in China led to set off the great debate of the community again on CSR. Large numbers of reports by the media, the public pay unprecedented attention to the CSR. In 2010, the Chinese public CSR awareness report shows: $50 \%$ of the public think that the status of the CSR has impact of purchase options, the public trust in new products or services to do better and more reliance on its brand. The corporate reputation is very important. The researchers believe that performance of the CSR is to establish a reputation for social activities, and it is the means difficult to imitate. The correlation between the CSR and consumer buying behavior is very close, so the products of the corporation with good quality are welcomed by consumers. The image of CSR can rely on reputation to attract more investors and partners.

\section{Analysis on the Implementation, Problems and Reasons of the CSR}

The rise of the CSR movement in the western developed countries in the 1990s, since 2003, the thoughts of the CSR began to heat up in China. But by the end of 2006 only five central enterprises released social responsibility reports in China, one hundred in 2011, the increase in the number of the CSR report can be said that it is the world's leading.

China is the period of the deepening reform and opening up, acceleration the transformation of economic development in the crucial period, and the community is increasingly high expectations on the CSR. More and more Chinese enterprises pay more attention to fulfill social responsibilities which is a major force to change their mode of development, carry out sustainable development. The CSR reports appear steady growth trend. The development of the CSR enters the stage of stable development. There are certain differences among different types of practice of the CSR, and the level of the practice of the CSR of the state-owned corporations is the 
highest.

\subsection{The Implementation}

In recent years, a series of effective measures have been performed that make central enterprises continuously improve the ability and the level of the social responsibility work, and achieved good results. SASAC published guidance on the CSR in early 2008 that put forward the concept, objectives, content and measures of the CSR, to provide clear guidance for the central enterprises to fulfill their social responsibility. The CASS-CSR1.0 and CASS-CSR2.0 were released in 2009 and 2011.The concept and awareness of the CSR constantly are enhanced, and the social responsibility work management system gradually is made perfect. The central enterprises have established social responsibility organization management systems which there are more than 50 enterprises to establish social responsibility committee, or social responsibility leadership team, and so on.

At the end of 2011, the existing 76 central enterprises have released social responsibility reports or sustainability reports, CNPC, China Minmentals Corporation and Sinosteel Corporation released the country reports which have obtained the evaluation home and abroad highly. Actively to explore the useful practices and management model, what the central enterprises fulfill their social responsibility has also been widely recognized by the community.

For example, China Mobile, the State Grid Corporation of china, and other CSR practice cases have been selected into textbook by the Harvard Business School, University of Cambridge. China Mobile has been selected into the Dow Jones Sustainability Index (DJSI) for four consecutive years, and China Minmentals Corporation got the environment Pioneer honor of the United Nations Global Compact. These events marked the level of management and performance of CSR of the central enterprises has been one of the world-class enterprises.

Facts have proved that the proportion of private economy in the national economic output is getting higher and higher, as an important part of the diverse forms of ownership in China is very dynamic, and the status and role cannot be ignored. There are more and more private companies whose development history is just only 20 years. Some of them are still in the early stage of development of one-sided pursuit of profit, and more than $90 \%$ of them are SME which are struggling to survive, so there is no time to attend to this issue of CSR, and even have no consciousness.

According to the distribution of the sample companies controlling shareholder of Chinese Listed Corporate Social Responsibility Report 2008 which was published by the Shanghai National Accounting Institute, we can see that $12 \%$ central state-owned enterprises released independent social responsibility reports, among them the SASAC, central SOEs and other enterprises disclose the highest index of more than 66 points, but private enterprises and collective enterprises disclose the lowest index of more than 1 points.

China CSR Ranking 100 list published on China CSR Conference in 2009, ranked the top $2075 \%$ state-owned enterprises, private enterprises accounted for only $25 \%$, of 15 lacks of social responsibility cases 13 for private enterprises.

The 6th international forum on the CSR, 2010 China CSR Practice Benchmark Report: the social responsibility performance of the China's large enterprises in the various fields is better than SME's. The private enterprises mainly made of the SME involved in the assessment, and the proportion increased every year, rising from 27 percent in 2007 to 42.5 percent in 2010, which showed increasingly high degree of attention on the practice of the social responsibility for SME.

The end of October 2011, the China Youth Daily Social Investigation Center through the public network and Sina online surveyed one thousand corporations: for the different types of the CSR, the public comment from high to low: foreign companies $(30.8 \%)$, state-owned enterprises $(28.4 \%)$, private enterprises $(18.7 \%)$ and joint ventures (7.5\%).

Announced on November 8, 2011 China CSR Report showed that the overall social development of Chinese enterprises Responsibility Index is low, the state-owned enterprises composite score 31.7 points higher than private enterprises and foreign, and the central enterprises got the highest scores. The $70 \%$ of the enterprises seriously are lack of social responsibility, 26 companies score 0 or negative. Compared with 2010, the state-owned development of CSR index rose to 31.7 points from 28.9 points. Among them, the development index of the central enterprises increase obviously, the social responsibility development index of private enterprise dropped to 13.3 points from 13.9 points, social responsibility development index of the foreign-funded enterprises rose from 8.1 points to 12.6 points. 


\subsection{The Issues and the Reasons}

After the SASAC proposed all central enterprises shall release social responsibility reports by the end of 2012, the social responsibility reports released by the central enterprises increased sharply, but along with them the problems exposed are also evident. Passive disclosure of the report of the CSR accounted for the vast majority. The state-owned enterprises coordinated with government policy motives, private enterprises met the requirements of the market and customer.

These years the central enterprises have gotten a lot of achievements, but there are still many challenges and problems, the most prominent of which was that a number of business leaders had shallow awareness, the CSR management system was still inadequate, some CSR communication mechanisms has yet to be sound and also are lack of effective social responsibility communication mechanisms, The ability of transparently operating, communicating with stakeholders and shaping the brand awareness needs to further improve for the central enterprises . The social responsibility reports of many central enterprises were found that they only introduced enterprise business and charitable activities.

The policies and regulations for large enterprises, and there is no standard for SME to fulfill the social responsibility. At the moment, China's law on CSR information disclosure has been lacking, only regulations are for the introduction of individual responsibility information disclosure. On the one hand, the degree of perfection of the regulations is not enough and the requirements of the existing regulatory are too weak; on the other hand, the driving force of the government is still quite weak. In addition to the strict rules of disclosure of financial information of listed companies by the SFC, the government is to encourage rather than mandatory approach, and did not provide clear disclosure requirements. It was the absence of law and government and other external pressures, so corporations can not report the bad news.

In addition to the officials, what people do not concern is also an important factor. Currently the public understand corporate social image by the publicity materials of the enterprises themselves, the official website for the main channel less than 50\%, Chinese enterprises have been the craze of social responsibility report, nearly half of the survey do not even have heard of CSR report. This is a departure phenomenon: public concern the performance of the fulfilling their social responsibility of the enterprises, but ignore the social responsibility to voluntarily disclose information.

\section{Measures Analysis to Strengthen the Corporate Social Responsibility}

The CSR is not only the requirements of the enterprises, at the same time needs the joint efforts of government, media and consumers. We should study from the developed countries which have years of experiences, but we must think about the reality. We all know that China is still the largest developing country, so we have to bear the social responsibility which cannot divorce from the national conditions.

\subsection{The Government Guidance}

1) Properly handle the relationship between actively promotion and distributed implementation, it is necessary to firmly strengthen CSR policy orientation, give publicity, raise awareness, enhance consciousness and take into account the national conditions.

2) The second is to properly handle the government-oriented, intermediary services, and business relations, the government plays the role of macro-guidance and supervision of law enforcement, through policy guidance, constraints enterprises evade social responsibility behavior, attention should be paid to play the coordinating role of intermediary institutions ,to promote the intermediary organizations to use training and other means to enhance the understanding of the CSR, and strengthen the industry self-regulation.

3) The third, to properly handle the relationship between CSR and our existing laws and regulations, to bear corporate social responsibility in terms of China's relevant laws. The government not only should further improve China's relevant laws and regulations, to make specific disciplinary provisions for violations of the law, but also to encourage enterprises to more involved in social welfare undertakings and strengthen social responsibility information disclosure.

\subsection{Industry Implementation}

As industry organizations are the coordinator of the order within the industry, social responsibility report is to maintain the normal order and long-term interests of the industry. And industry associations should actively explore the establishment of the standard system, information dissemination mechanisms and evaluation system of the CSR, to promote the industry CSR. 


\subsection{Enterprises Promotion}

The enterprise shall establish and improve stakeholder management systems, attach importance to the stakeholders at the same time, actively enhance the level of responsibility to fulfill other stakeholders. First, strictly compliance with the laws promulgated by the state are the bottom line of social responsibility; second enterprises should accept supervision. Third, the enterprises carry out research and development in the technical aspects, and lead the trend of environmental protection.

\subsection{Society Participation}

The public and news media are important forces to promote the industry to fulfill responsibilities. Social attention for social responsibility is rising, consumers, workers, news media and the general public from their point of view, to urge enterprises to fulfill their social responsibilities. The news media should create a good social atmosphere as an important focus, to step up publicity efforts to enhance CSR awareness, propagate the effect and experience of the corporation return to the community, enhance the public awareness and participation, building environment to promote industry social responsibility report released and the implementation.

\section{References}

Dong, W. (2010, December 20). 90\% of the Corporate Social Responsibility Report Makes No Mention of Negative Information. China Youth Daily.

Global Spirit. (2010, September 16). A-Share Listed Companies in Social Responsibility Report Rrating Methodology. News Network.

Hu, G. Y. (2010). The Study of the Basic Issues of Corporate Social Responsibility Theory- Based on Value Creation Perspective and the Distribution of Benefits. Shanghai Jiao Tong University Doctoral Thesis, 2010.

Shanghai National Accounting Institute. (2008). China's Listed Companies Social Responsibility Report 2008. Beijing Economic Science Press.

The Blue Book: 2011. (2011, November 8). Corporate Social Responsibility Overall Low Development Index. XinHua Network.

Zhang, L. (2010). The Empirical Analysis of the Relation of the Corporate Social Responsibility and Corporate Value- Empirical Evidence from Listed Companies in China. Jiang Xi University of Finance.

\section{Note}

China Youth Daily, January 10, 2011.

People's Daily, November 18, 2011.

China Securities Journal, November 9, 2011.

CCTV Network, June 20, 2011.

Economic Times, February 25, 2006.

Http://finance.sina.com.cn 